\title{
Renovation and renewal
}

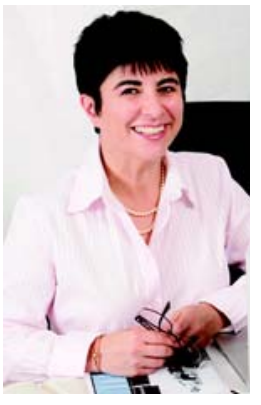

Annette Katelaris

Edito

akatelaris@mja.com.au

doi: 10.5694/mjall.c0905

that over $80 \%$ of respondents to an Australian survey (quoted by Olsen et al) believe that they have been exposed to asbestos at home or at work.

In an accompanying editorial, Gordon and Leigh (page 247) note that Australia already has the highest rate of mesothelioma in the world. They stress the importance of maintaining accurate clinical data through the use of centralised mesothelioma registries, in the hope that these will sound both national and global warnings of the dangers of asbestos. Although asbestos has essentially been banned as a building material in Australia and most of the world, it is still used in some of the most populated countries, such as China, India and Indonesia.

They counsel that we need to be vigilant in maintaining awareness of the risks of asbestos exposure during home renovation, and lament that, to this day, there are no systematic warnings to ensure that people are aware of asbestos risks in their homes. Given the widely publicised legal liability of the companies that were involved in the production and distribution of asbestos-related products, the lack of these warnings is mystifying.
All doctors, and indeed all Australians, need to be aware of this rise in the incidence of malignant mesothelioma associated with home renovation. It is fitting that this important issue is aired in the MJA.

$$
* * * *
$$

Today's MJA has a new look. I hope that you find the new layout attractive, engaging and readable. We have added a news section, and increased our focus on commentary and opinion. Our internal processes have been revised to ensure that we bring you Australia's best research and comment in the most timely way possible. In particular, I wish to welcome our new Specialist Editorial Advisers, all leaders in Australian medicine, who will help guide the editorial direction of the Journal.

The $M J A$ is committed to the highest standard of publishing, and to preserving its deserved reputation for accurate, ethical, transparent and trustworthy content. The redesign aims to improve the quality of medical information and comment in the Journal and to enhance the way this information is communicated. It will provide a platform for the Journal's continued evolution, soon to include an improved electronic and web presence.

This Journal is written by doctors, for doctors. It is the principal forum for communication between all branches of the profession. Media coverage of research and issues addressed in the MJA gives the profession an additional voice in the Australian community. I hope that you will feel a sense of ownership of the Journal and the direction it is taking, and the freedom to contribute to it.

I thank all the staff of the Journal for their expertise and effort in making this redesign happen - we have come a long way in a short time. I would also like to take this opportunity to thank the members of the Journal's Content Review Committee and the thousands of peer reviewers who generously give their time and energy to help make the MJA Australia's premier general medical journal.

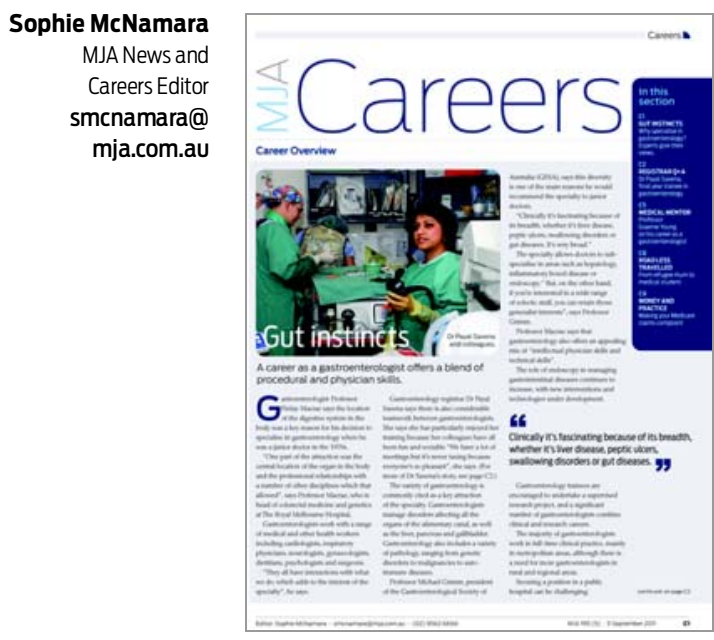

\section{Career stories to inspire you}

The relaunched MJA Careers has a new design and new sections to inspire and inform your medical career. In this issue, the new Road Less Travelled section focuses on a first-year student in her 40s who has come to medicine after being a refugee, raising a family and working as an engineer (page C8). We talk to gastroenterologist Professor Graeme Young about how medicine has taken him from grassroots research in Papua New Guinea, to helping pave the way for Australia's bowel cancer screening program (page C5). As always, MJA Careers contains relevant information about running a medical practice, and in this issue we explain how to ensure that your Medicare claims are compliant (page C9). The new-look MJA Careers also contains a wealth of career and educational opportunities, so flick to its new location at the back of the Journal to make your job search easier. 